\title{
Editorial:
}

\section{Industry 4.0: More than a Technological Revolution}

\author{
Industria 4.0: más que una revolución tecnológica
}

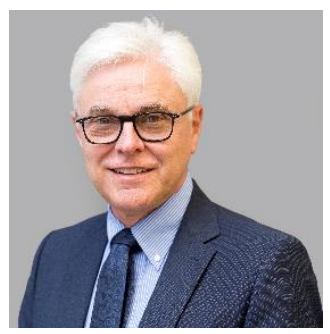

Detlef Zuehlke

Honorary member of the executive board SmartFactory ${ }^{\mathrm{KL}}$ e.V. and retired Professor for Factory Automation Innovative Factory Systems German Research Center for Artificial Intelligence

E-mail: zuehlke@smartfactory.de https://doi.org/10.22430/24223182.1438

Since its first appearance in April 2011, the term Industry 4.0 has become synonymous with the production of the future. Nearly all industrialized countries around the globe have set up research programs and industrial support projects, and they encourage SMEs and government agencies to actively shape those developments and keep their industries competitive.

Today, the Industry 4.0 has already arrived in factories, at least in the highly developed regions of the world. More and more companies adopt its ideas and convert their manufacturing plants into smart production facilities. Furthermore, many equipment suppliers offer a broad range of smart products for machine control. So, can we proudly say "mission accomplished"?

Yes, but not completely yet...

Until today, most Industry 4.0 activities can be observed in the field of smart control systems. We can use internet technologies down to the field level, provide workers with smart devices for better process control, and set up modular factories just by easy plug ' $n$ ' play. But we also recognized that deep changes that have affected market needs require even further adaptation. When a piece of production equipment becomes a standardized building block comparable to a Lego brick, the next step is to also turn entire factories into building blocks in a distributed production network. Thus, an 
efficient and sustainable supply chain becomes the overall goal and, as a result, the general objective of smart manufacturing must be seen from a much broader perspective today.

New technologies appear increasingly faster and find their application in production environments. TSN/SDN Ethernet will offer a complete compatible internet communication standard with real-time capabilities; this wire-based solution will soon be completed with $5 \mathrm{G}$ wireless cells that provide highspeed wireless control with an extremely low latency. Regarding message transport, OPC UA will be the worldwide network standard and soon offer the important publish-subscribe mechanism. Nevertheless, appropriate standards for its application and interoperability are still a work in progress. Continuing with the Lego brick example, we also need a standardized communication shell around all our bricks (devices) called Asset Administration Shell, which defines a complete set of communication and service standards in order to easily connect any device from any supplier worldwide to a factory network.

Thanks to such powerful and extended networks, we will have direct access to huge amounts of data generated by sources that range from administrative and engineering systems down to each sensor and actuator. But just accessing the data is not enough; we need to develop techniques to analyze it and convert it into useful information and knowledge. That is the domain of Artificial Intelligence and, over the next years, we will see a fast implementation of Al techniques like pattern recognition, reasoning, and deep learning. In the long run, this will allow us to build highly complex, highly agile autonomous systems, which are needed for the production of personalized goods on customer demand at an affordable cost.

However, technical developments must generate market demand to finally be commercially successful. Again, this seems to be the case in highly industrialized regions around the world. Smart technologies will offer the right solutions for them to become even more productive than before. Notwithstanding, less developed regions must be enabled to participate in this Fourth Industrial Revolution as well. Their typical business model, based on offering low-cost labor to the rest of the world, will no longer be successful. With more customized production and faster delivery to final customers, production centers must move closer to customer markets. As a result, the worldwide market as we know it today will be restructured as more regional markets like in north America, Europe, or Asia. And all those markets will require new solutions for setting up supply chains and manufacturing networks based on knowledge, human resources, and customer needs.

In conclusion, industrialized countries are not only suppliers of technologies to the rest of the world, they should also accept their responsibility to help less industrialized regions to find and implement their future business models in an interconnected world. For example, I deeply appreciate the work being carried out by the World Economic Forum and the United Nations Industrial Development Organization to shape the future for all mankind. 